\title{
The Characterisation of an Alpha Spectrometry System using a Certificated Standard Source
}

\author{
Nurgül Hafizoğlu ${ }^{*}$ \\ 1* İstanbul University, Faculty of Science, Departmant of Physics, İstanbul, Turkey, (ORCID: 0000-0002-0869-070X), nurgulhafizoglu@istanbul.edu.tr
}

(First received 07 August 2021 and in final form 25 December 2021)

(DOI: 10.31590/ejosat.979887)

ATIF/REFERENCE: Tarım, U.A. \& Gürler, O. (2018). Source-todetector Distance Dependence of Efficiency and Energy Resolution of a 3"x3" NaI(Tl) detector. European Journal of Science and Technology, (31), 928-932.

\begin{abstract}
The calibration parameters of a high resolution two-chamber alpha spectrometer dedicated to detect alpha radiation in environmental samples were evaluated and confirmed using a certified standard source containing ${ }^{237} \mathrm{~Np},{ }^{241} \mathrm{Am}$ and ${ }^{244} \mathrm{Cm}$ nuclides. The resolution and efficiency characteristics for the two ion-implanted solid state detectors (ULTRA AS series) in this system were evaluated at all possible detector-source distances. The characteristics related to the performance of alpha detectors against the alpha radiation emitted from the standard source used in the measurements and the results obtained were compared in detail.
\end{abstract}

Keywords: Alpha spectrometry, Energy and efficiency calibration, FWHM, Self-absorption.

\section{Sertifikalı Standart Kaynak Kullanılarak Alfa Spektrometre Sisteminin Karakterizasyonu}

$\ddot{\mathbf{O z}}$

Çevresel numunelerdeki alfa radyasyonunu tespit etmek için yüksek çözünürlüklü iki odacıklı bir alfa spektrometresinin kalibrasyon parametreleri, ${ }^{237} \mathrm{~Np},{ }^{241} \mathrm{Am}$ ve ${ }^{244} \mathrm{Cm}$ çekirdeklerini içeren sertifikalı bir standart kaynak kullanılarak değerlendirilmiştir ve doğrulanmıştır. Bu sistemdeki iki adet iyon implanteli katı hal dedektörünün (ULTRA AS serisi) çözünürlük ve verim özellikleri, olası tüm dedektör-kaynak mesafelerinde değerlendirilmiştir. Ölçümlerde kullanılan standart kaynaktan yayılan alfa radyasyonuna karşı alfa dedektörlerinin performansına ilişkin özellikler ve elde edilen sonuçlar detaylı olarak karşılaştırılmıştır.

Anahtar Kelimeler: Alfa spektrometresi, Enerji ve verim kalibrasyonu, FWHM, Self-absorption.

* Corresponding Author: nurgulhafizoglu@ istanbul.edu.tr 


\section{Introduction}

Alpha spectrometry is an analytical measurement technique, that is widely used in many applications such as nuclear decay measurements, geological studies, ${ }^{210} \mathrm{~Pb}$ analysis to determine sedimentation rate, the high sensitivity detection of alpha emitting particle radionuclides in environmental samples (sediment, soil, food products etc.) and in biological samples (marine products etc.) (Aggarwal, 2016; Calin et al., 2013a).

Alpha detectors have low background and high efficiency. These features mean that they have higher sensitivity for detecting radionuclides than high purity Ge detectors used to detect gamma rays. These properties ensure that samples with low levels of radioactivity can be detected correctly in various applications (Saidoua et al., 2008).

The alpha spectrometer system described here is based on Ion implanted charged particle detectors. They are made by bombarding semiconductor crystals with ions from an accelerator. This process is called ion implantation (Cember and Johnson, 2009; Johansson, 2008; Knoll, 2000; Leo, 1994). Ions are implanted in both the entrance window and the back contact of the detectors. This has the following advantages. The extremely thin (about 500 Á) entrance windows are implanted with boron ions. This minimises the energy straggling of the alpha particles entering the detector and thus improves the resolution of the ion implanted charged particle detectors. In addition, the window, which is resistant to mechanical effects, can be easily cleaned in the case of contamination (Vajda et al., 2020; ORTEC, Certificate of Conformance Quality Assurance Data (QAD) Sheet). The energies of the alpha particles are completely absorbed by the detector and ion pairs are produced with an amplitude proportional to the absorbed energy. Additionally, the detector chamber and the sample are kept under high vacuum to prevent the loss of alpha particle energy in interactions with atoms in the air. The energies of the alpha particles can be measured if the detectors are calibrated using suitable sources of radionuclides that emit alpha particles of known energy (Calin et al., 2013a; Knoll, 2000; Vajda et al., 2020).

The aim of this study is to characterise the alpha detectors in the Nuclear Physics Research Laboratory of İstanbul University and evaluate the performance of the system by applying appropriate methods for their calibration.

\section{Material and Method}

The alpha spectrometer is used for the measurement of alpha radiation from environmental and biological samples (Carvalho, 2011; Hafizoğlu et al., 2020; Kim et al., 2017). The system is composed of two counting chambers (Alpha Duo, ORTEC), each one containing on ion-implanted charged particle detector, which take measurements independently. Each detector has its own electronics, multi-channel analyser and vacuum pump (ALPHA-MINI-PPS). The detectors are of the ULTRA AS, BU-020-450-AS model, with an active area of $450 \mathrm{~mm}^{2}$ (ORTEC, Certificate of Conformance Quality Assurance Data (QAD) Sheet). Figure 1 shows the block diagram of the single detector system. The detectors have an applied operating voltage of $50 \mathrm{~V}$ and measure particles over an energy range of $0-10$ $\mathrm{MeV}$. The energy resolution (FWHM) of the ion-implanted detectors is guaranteed by the manufacturer to be $\leq 20 \mathrm{keV}$ for alphas of $5.486 \mathrm{MeV}$ energy when the distance between the detector and the source is equal to the detector diameter. The maximum sample size is $51 \mathrm{~mm}$ and in each counting chamber the detector-source separation can be set at 10 distances from 1 to $41 \mathrm{~mm}$. The vacuum functions, hardware controls, data acquisition settings, detector voltage and leakage current parameters of each counting chamber can be controlled independently with MAESTRO ${ }^{\circledR}$ MCA software (ORTEC, 2014).

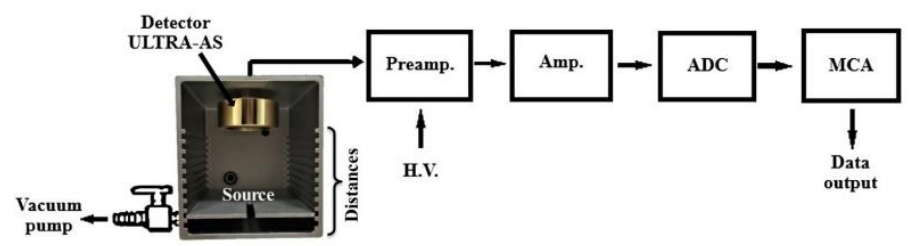

Fig 1. Schematic illustration of the alpha spectroscopy system with one chamber as an example. All possible detector-source distances can be seen.

All of the measurements were made with a certified standard alpha source. It was a multi-nuclide standard (Eckert \& Ziegler Isotope Products) source containing the radioactive nuclides of ${ }^{237} \mathrm{~Np},{ }^{241} \mathrm{Am}$ and ${ }^{244} \mathrm{Cm}$ that emit alpha particles with energies 4.79, 5.49 and 5.81 MeV respectively (Eckert \& Ziegler Nuclitec $\mathrm{GmbH} ., 2016)$. The source takes the form of a stainless steel disc with the radionuclides deposited in the centre of one surface. The disc has a thickness of $0.5 \mathrm{~mm}$ and diameter of $25 \mathrm{~mm}$. The radioactive material is deposited in a circle of $7 \mathrm{~mm}$ diameter at the centre of the disc. The activities of the ${ }^{237} \mathrm{~Np},{ }^{241} \mathrm{Am}$ and ${ }^{244} \mathrm{Cm}$ nuclides in the standard alpha source at the time of the experiments were approximately $150 \mathrm{~Bq}, 100 \mathrm{~Bq}$ and $100 \mathrm{~Bq}$, respectively, based on the activities at the time of manufacture and known half lives of the three nuclear species involved (Eckert \& Ziegler Nuclitec GmbH., 2009; Eckert \& Ziegler Nuclitec GmbH., 2016). If the diameter of the source is larger than that of the detector then the efficiency is reduced because of greater energy straggling in the detector window (CANBERRA, 2011). Accordingly, the diameter of the standard alpha source has been chosen equal to the detector diameter. As the source thickness increases, the greater the self-absorption of alpha radiation. As a result the broadening of the peaks means poorer energy resolution and the tailing increases (Vajda et al., 2020). Thus a standard alpha source that was homogeneous and thin was obtained from the manufacturer to reduce these effects. The ULTRA AS alpha detectors were calibrated in energy using the known energies of the three radionuclides in the alpha standard source. In order to determine the efficiency and resolution parameters of the two detectors in the system a series of measurements, each 100 seconds long were taken with the standard source at all possible detector-source distances within the counting chambers. Figure 2 shows an example of a spectrum from detector one.

From the spectra, the efficiency of each detector was calculated by dividing the measured counts per second by the known number of alpha decays per second for each detectorsource distance. Similarly the energy resolution of the detector was determined by calculating the full width at half maximum (FWHM) of the peaks.

Depending on the results, the detector-source distances with the best energy resolution and efficiency that we consider as optimum were determined for two counting chambers. These 
distances have also greatest sensitivity to the detection of alphas emitted from a low-activity source. Additionally, the variations of solid angles according to all possible the detector-source distances were determined by considering the geometries of both detectors and standard source.

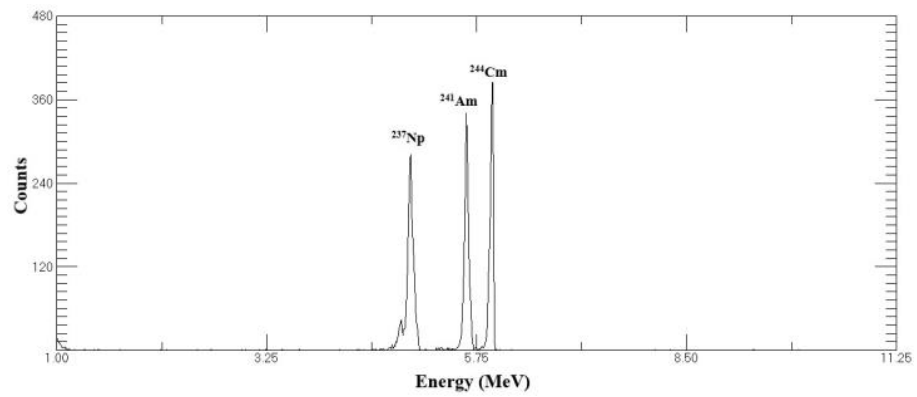

Fig 2. An example of the alpha particle spectrum from the certified standard source seen in the first detector. One can see clearly the peaks induced by the known alpha particles from ${ }^{237} \mathrm{~Np},{ }^{241} \mathrm{Am}$ and ${ }^{244} \mathrm{Cm}$ at $4.79, \quad 5.49$ and $5.81 \mathrm{MeV}$, respectively. This spectrum was recorded at a detector-source distance of $8 \mathrm{~mm}$ and was used to determine the efficiency and energy resolution of the alpha spectroscopy system at that setting. The dead time effects in all measurements was quite low.

\section{Results and Discussion}

\subsection{The Determination of the Alpha Detector Efficiency}

The detector efficiencies based on the measurements taken with the standard disc source at all possible detector-source distances in the two counting chambers in the alpha spectroscopy system are presented in Figures 3 and 4. These results were fitted to the function $y=a x^{-b}$ and the fitting parameters $\mathrm{a}$ and $\mathrm{b}$ were determined.

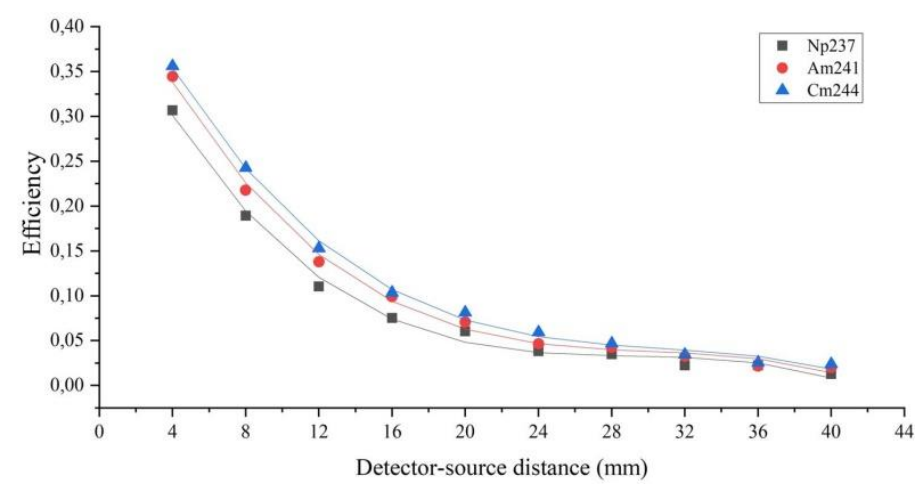

Fig 3. The efficiency of the first counting chamber based on measurements with the standard alpha source is shown as a function of detector-source distance (see text). The separate curves are for alpha particles from the three radionuclides in the source (see text).

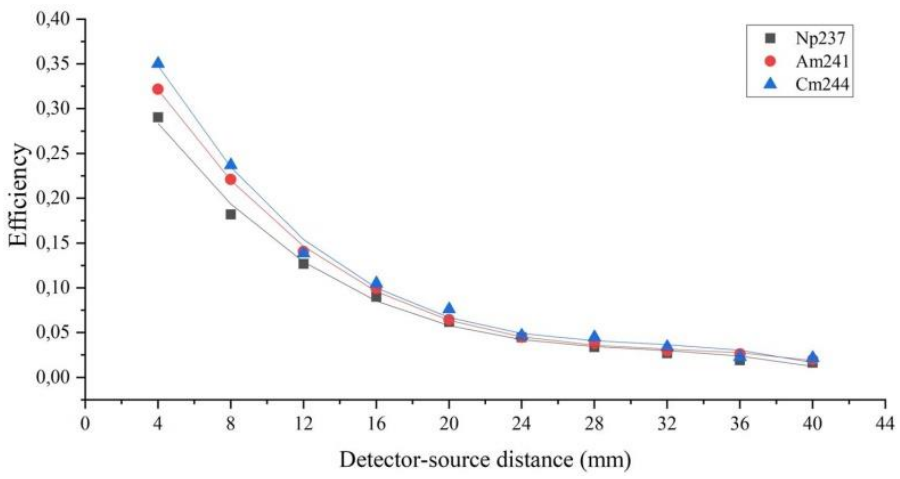

Fig 4. The efficiency of the second counting chamber based on measurements with the standard alpha source is shown as a function of detector-source distance (see text). The separate curves are for alpha particles from the three radionuclides in the source (see text).

In the efficiency curves shown in Figures 3 and 4 one sees that the three curves for alphas with different initial energies separate more rapidly as the detector-source decreases. This is essentially a geometrical effect due to the increase in the number of alpha particles passing through a greater thickness in the window and the resulting increase in the straggling effect. Conversely constant efficiency is nearly reached for the higher detector-source distances. As a result of these measurements and calculations, the detector-source distances with the best efficiency values were determined for both alpha detectors.

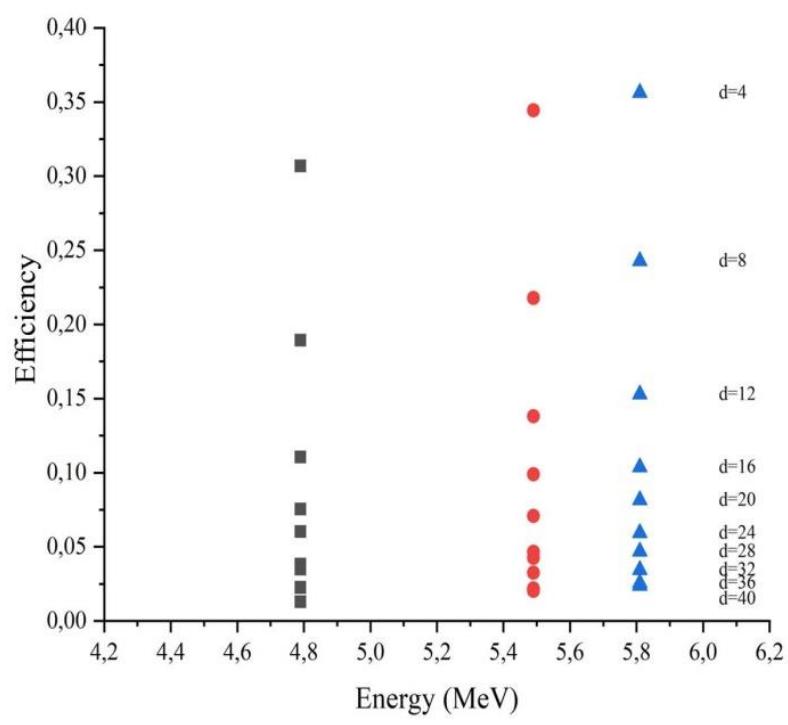

Fig 5. The measured efficiencies at different detector-source distances for alpha particles of the three different energies of particles from the standard source (see text). The black, red and blue colours represent the radionuclides of ${ }^{237} \mathrm{~Np}(4.79 \mathrm{MeV})$, ${ }^{241} \mathrm{Am}(5.49 \mathrm{MeV})$ and ${ }^{244} \mathrm{Cm}(5.81 \mathrm{MeV})$, respectively. The straggling effects due the changing geometry are clearly visible.

The same information about the measured efficiency is shown in Figure 5, where we see that the detector efficiency depends on the measurement geometry and the detector-source distances (Calin et al., 2013b). Therefore, it is concluded that the detector-source distance should be as small as possible in order to obtain high measurement efficiency. The maximum efficiency values of ULTRA AS, BU-020-450-AS model alpha detectors in the first and second counting chambers of the alpha spectroscopy system for the ${ }^{241} \mathrm{Am}$ radionuclide are 0.344 and 0.322 , respectively. 


\subsection{The Determination of the Resolution of the Alpha Detector}

Energy resolution is one of the most fundamental parameters in detectors designed to detect the energy of the incident radiation. It is this parameter that determines how readily one can distinguish peaks with similar energies in a spectrum. Generally, the resolution is defined as the FWHM of the peak at a certain energy in the spectrum (AMETEK Materials Analysis Division, Lecture Notes; Leo, 1994).

The FWHM is required for the energy resolution evaluation of an alpha spectroscopy system and is dependent on the statistical fluctuation in the number of the electron-hole pairs produced in the detector, the charge collection and the energy losses of the particles in the thickness of the detector entrance window that they pass through. It also depends on the properties of the alpha-particle source (Vajda et al., 2020).

The thickness of the detector entrance window is an important parameter that dictates the straggling effect on the alpha particles and hence determines the energy resolution. This effect on the detector resolution is especially significant in thick detector windows and when the particle enters the window at a shallow angle. Hence the problem when the source is close to the detector or is much larger than the detector surface. If the entrance window of the detector is as thin as possible, the energy loss of alpha particles in the window is reduced and high resolution can be achieved (Eckert \& Ziegler Nuclitec GmbH., 2009; Vajda et al., 2020). ORTEC, ULTRA AS, BU-020-450-AS model detectors in the alpha spectrometer have entrance windows of $500 \AA$ ( $(\sim 50 \mathrm{~nm})$ thickness (ORTEC, Certificate of Conformance Quality Assurance Data (QAD) Sheet).

Also, the detector-source distance and geometry are parameters that affect the detector resolution. The average of alpha particles entering the detector will increase at distances where the source is close to the detector. Again it is because some of the alpha particles have a larger path in the source hence straggling increases. Therefore, higher energy straggling and an increase in FWHM values directly associated with detector resolution are expected (CANBERRA, 2011).

ORTEC, ULTRA AS alpha detectors are characterized by examining the pulse height distributions obtained from the standard disc source with ${ }^{237} \mathrm{~Np},{ }^{241} \mathrm{Am}$ and ${ }^{244} \mathrm{Cm}$ nuclides. At the same time, the energy calibrations of the detectors were carried out with the certified standard disc source. From the spectra obtained at all detector-source distances in two counting chambers, the FWHM values representing the separation of close energy peaks were determined.

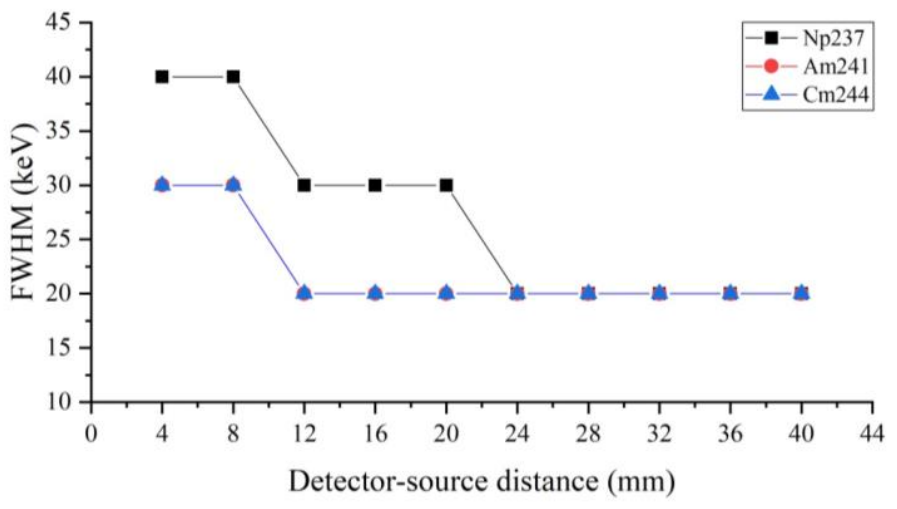

Fig 6. The measured FWHM for the alpha particles from ${ }^{237} \mathrm{~Np}$ (4.79 MeV), ${ }^{241} \mathrm{Am}(5.49 \mathrm{MeV})$ and ${ }^{244} \mathrm{Cm}(5.81 \mathrm{MeV})$ nuclides in the detector the $1^{\text {st }}$ counting chamber in the alpha spectrometry system.

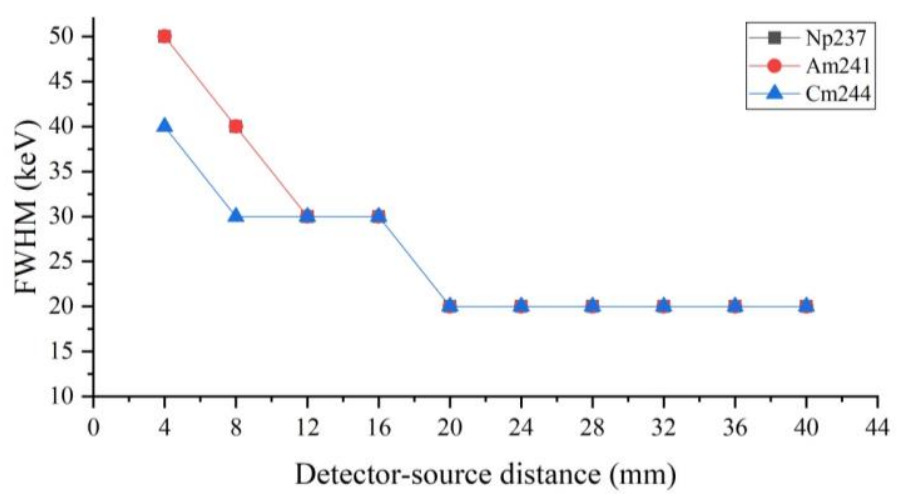

Fig 7. The measured FWHM for the alpha particles from ${ }^{237} \mathrm{~Np}$ (4.79 MeV), ${ }^{241} \mathrm{Am}(5.49 \mathrm{MeV})$ and ${ }^{244} \mathrm{Cm}(5.81 \mathrm{MeV})$ nuclides in the detector the $2^{\text {nd }}$ counting chamber in the alpha spectrometry system.

The measured FWHM values, or in other words the energy resolution, as a function of detector-source distance for both counting chambers are shown in Figures 6 and 7. It can be seen that for distances $\geq 20 \mathrm{~mm}$ the FWHM values are constant and increase significantly at shorter distances.

The energy resolution of the detector of $20 \mathrm{keV}$ (5.486 MeV for ${ }^{241} \mathrm{Am}$ nuclei) guaranteed by the manufacturer is observed at larger detector-source distances. At shorter distances the geometry results in greater energy straggling and hence poorer resolution. 


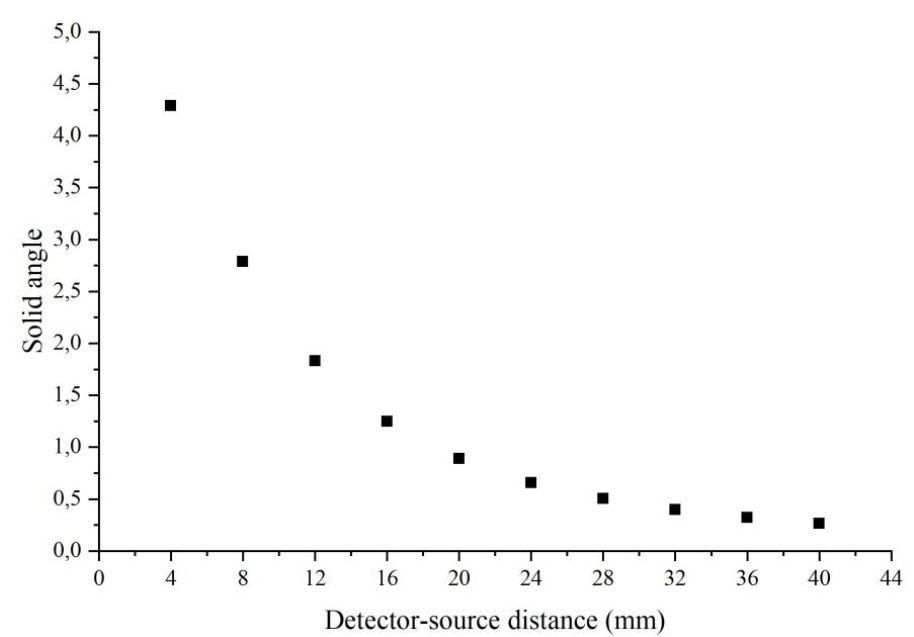

Fig 8. The variation of the detector solid angle according to the detector-source distances.

The best resolution for the ULTRA AS detectors in the alpha spectrometer system were obtained under the conditions where there is minimum energy straggling. This occurs for detectorsource distances consistent small solid angle values that lead to the detection of alpha particles emitted perpendicularly to the standard source and impinging on the detector surface at angles closer to $90^{\circ}$ on average.

The solid angle values for the two ULTRA AS detectors in the system for all detector-source distances in the range of 4-40 $\mathrm{mm}$ are shown in Figure 8.

\section{Conclusions and Recommendations}

In this work measurements were made of alpha particle spectra from a standard source to allow us to characterise the two-counting-chamber alpha spectroscopy system (Alpha Duo, ORTEC). The measurements allowed us to determine the main parameters such as the efficiency and resolution of 2 ULTRA AS detectors. From the results we were able to calibrate the system according to these parameters and to determine the solid angle parameter according to the detector-source distances. These parameters that determine the efficiency and resolution are optimum detector-source geometry, peak shape, radionuclide energy and counting rate etc in studies with alpha spectroscopy.

The results of the measurements show that the efficiency and energy calibrations of the alpha spectrometer system at the Nuclear Physics Research Laboratory of Istanbul University has been determined reliably. This ensures that any measurements are repeatable and that accurate measurements can be carried out with the system in the future.

\section{Acknowledge}

I sincerely thank my advisor Prof. Latife ŞAHIN YALÇIN and Prof. Ela GANIOGLU NUTKU for their valuable support and contributions.

\section{References}

Aggarwal, S.K. (2016). Alpha-particle spectrometry for the determination of alpha emitting isotopes in nuclear, environmental and biological samples: past, present and future. Analytical Methods, 8, 5353-5371.
AMETEK Materials Analysis Division, Lecture Notes, Understanding Energy Resolution, USA.

Calin, M.R., Saizu, M.A., Radulescu, I. (2013a). Assessments on energy and efficiency calibration of an alpha spectrometry system using standard sources. J Radioanal Nucl Chem, 298, $55-60$.

Calin, M.R., Saizu, M.A., Radulescu, I., Druker, A.E. (2013b). Experimental characterization of a multi-chamber alpha spectrometry system using standard actinide sources. Nuclear Instruments and Methods in Physics Research A. 705, 13-16.

CANBERRA, Application Note. (2011). Considerations for Choosing an Alpha Spectroscopy PIPS Detector.

Carvalho, F.P. (2011). Polonium $\left({ }^{210} \mathrm{Po}\right)$ and lead $\left({ }^{210} \mathrm{~Pb}\right)$ in marine organisms and their transfer in marine food chains. Journal of Environmental Radioactivity, 102, 462-472.

Cember, H. and Johnson, T. (2009). Introduction to health physics, $4^{\text {th }}$ ed. McGraw-Hill Companies Inc. New York, USA, ISBN: 978-0-07-142308-3.

Eckert \& Ziegler Nuclitec GmbH. (2009). Calibration Standards and Instruments Product Information. Germany.

Eckert \& Ziegler Nuclitec GmbH. (2016). Certificate. Germany.

Hafızoğlu, N., Sahin, L., Ganioğlu, E., Ağgez, G., Yıldırım Baştemur, G., İsel, P. (2020). Assessment of Natural and Anthropogenic Radioactivity of the Princes' Islands in the Sea of Marmara. Water Air Soil Pollut, 231:261, 1-16.

Johansson, L. (2008). Determination of Pb-210 and Po-210 in aqueous environmental samples, Thesis (PhD), Leibniz University.

Kim, S.H., Hong, G.H., Lee, H.M., Cho, B.E. (2017). ${ }^{210}$ Po in the marine biota of Korean coastal waters and the effective dose from seafood consumption. Journal of Environmental Radioactivity, 174, 30-37.

Knoll, G. (2000). Radiation detection and measurement, $3^{\text {rd }}$ ed. John Wiley \& Sons Inc. New York, USA.

Leo, W.R. (1994). Techniques for nuclear and particle physics experiments, $2^{\text {nd }}$ ed. Springer-Verlag, Germany, ISBN: 3540-57280-5.

ORTEC. (2014). Alpha Duo, Alpha Mega and Alpha Ensemble Integrated Alpha Spectrometer Hardware User's Manual. U.S.A., 932505.

ORTEC, Certificate of Conformance Quality Assurance Data (QAD) Sheet, ULTRA ${ }^{\mathrm{TM}}$, ENS-Detectors, Oak Ridge.

Saidoua, Bochud, F., Laedermann, J-P., Kwato Njock, M.G., Froidevaux, P. (2008). A comparison of alpha and gamma spectrometry for environmental natural radioactivity surveys. Applied Radiation and Isotopes, 66, 215-222.

Vajda, N., Pöllanen, R., Martin, P., Kim, C.K. (2020). Handbook of radioactivity analysis, fourth ed. Volume 1: Radiation Physics and Detectors, Chapter 5-Alpha Spectrometry, pp. 493-573. https://doi.org/10.1016/B978-0-12-814397- 